\title{
FOCUS AWARDS 2003
}
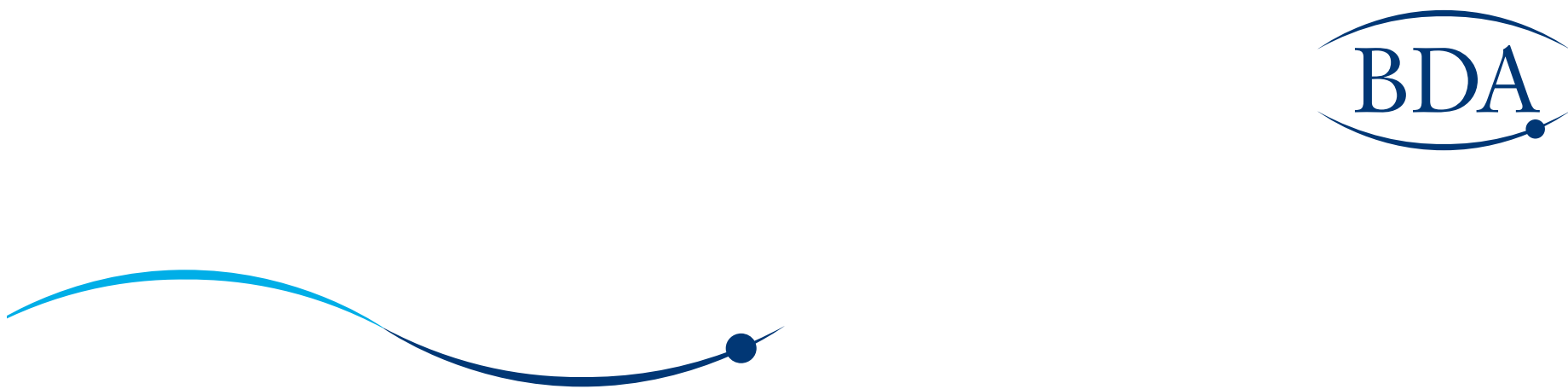

The Focus Awards 2003 recognised continuing excellence in dental patient care across the UK, Wales and Northern Ireland. The award for excellence in patient information and involvement went to Wessington Way Dental Practice, Sunderland; Naomi Davis finds out why.

The Wessington Way Dental Practice in Sunderland was the 2002 overall Focus Awards winner, so the team there had a difficult job bettering their already excellent service to patients. All credit to them, they were back at the Focus Awards 2003 to collect the prize for excellence in patient information and involvement.

The team at the practice in Sunderland have gone the extra mile in involving their patients in the running of their practice and keeping them informed of the activities of the practice and the progress they are making.

\section{PATIENT INVOLVEMENT}

One of the main initiatives that the practice has taken forward is the practice forum. Every two months, this group of selected patients meets to discuss events in the practice. They have proved useful at both coming up with ideas for the practice as well as stopping the practice from doing things that might have proved disastrous! The members of the forum are also involved in the annual staff $360^{\circ}$

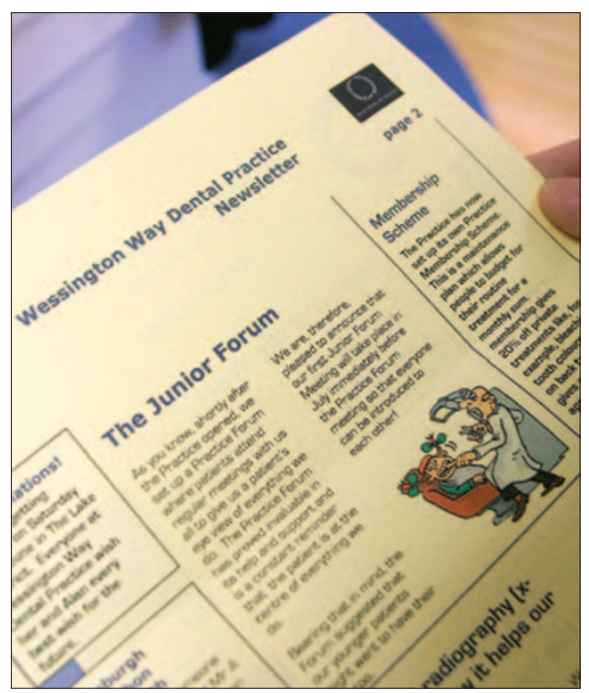

Practice newsletter announcing the junior forum

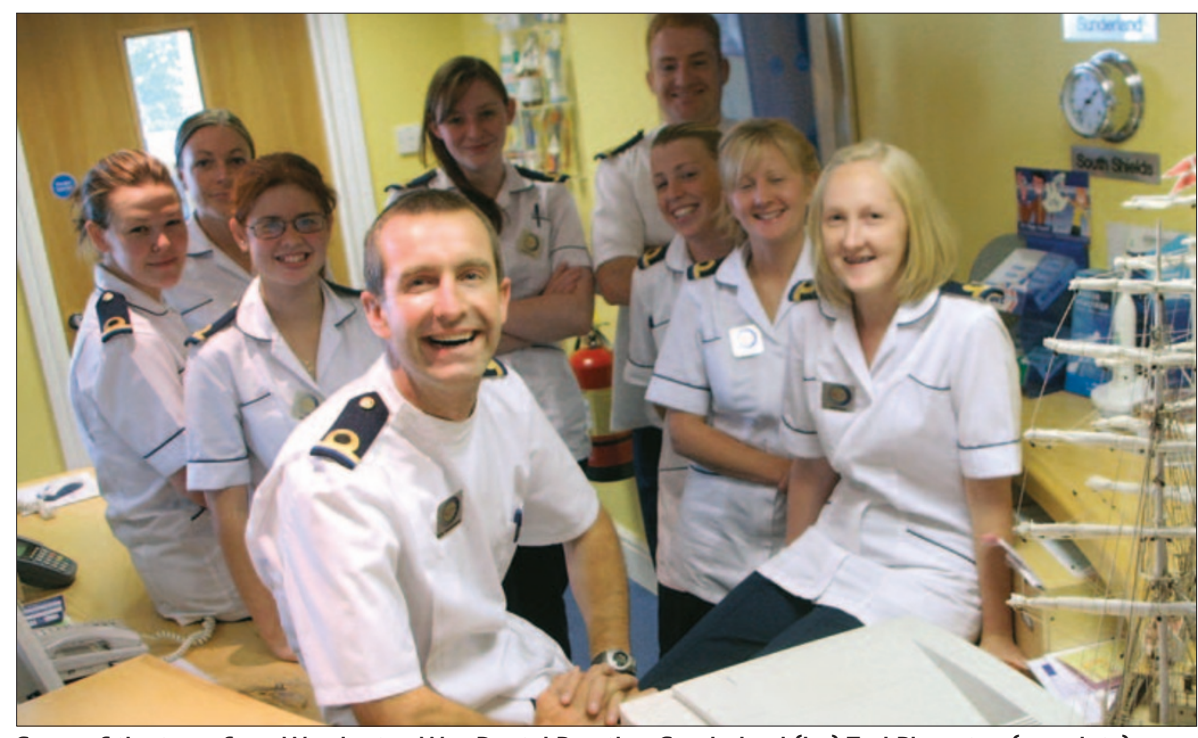

Some of the team from Wessington Way Dental Practice, Sunderland (I-r) Tori Plumpton (associate), Joanne Howes (dental nurse) Gemma Binks (dental nurse), Martin Anderson (practice owner), Samantha Allen (dental nurse), Richard Coates (associate), Lisa Bewick (dental nurse), Sharon Pattison (practice supervisor) and Amanda Taws (dental nurse)

appraisals. The practice forum is one of the reasons that they won the 2002 award, but success does not breed complacency here. For 2003, the team took the idea forward and developed a junior forum - a more informal version. This idea came from the original practice forum, and has so far recruited six members under the age of 18 .

The meetings for the junior forum take a kind of brainstorming style, and they come up with many ideas. Some are a little impractical, but many of them are really good. Among the lastest suggestions, there has been a relaxation room with dimmed lights and calming music for anxious patients to wait in; and a flag to have up on the practice flagpole at Christmas time. Martin Anderson, the practice owner, says 'the junior group just gush with ideas and suggestions!'

\section{PATIENT INFORMATION}

Wessington Way keeps their patients informed of their services through various media. There are leaflets and a welcome pack for new patients including information on local transport links and practice information, such as names of team members and how to arrange a home visit.

The practice also produces a newsletter which is printed four times a year to keep the patients up-to-date on developments at the practice. These tend to include useful information like what digital $x$-rays are and chatty information on who is getting married this year or local charitable events that the practice is involved in.

The practice website is very comprehensive with a virtual tour of the practice and a facility for people to email appointment requests. Alongside this there is an 'about us' and 'services' section.

The patient information board in the waiting room is always full and includes both clinical and social information. Clinical information includes things like 


\section{(DH) Department of Health}

The Focus Awards is a joint initiative between the Department of Health for England, the Department of Health, Social Services and Public Safety of Northern Ireland, Welsh Assembly Government and the British Dental Association.
Department of Health, Social Services \& Public Safety Northern Ireland

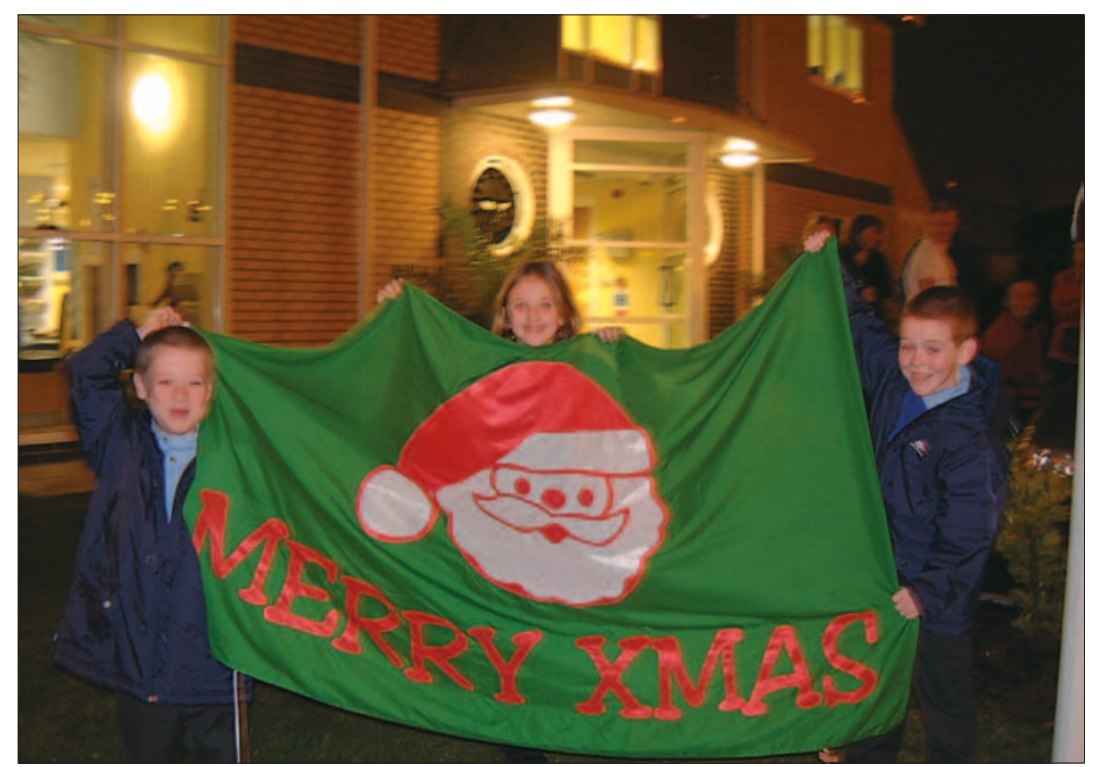

Members of the junior forum with the Christmas flag they suggested

oral health advice, the name of the member of staff proficient in sign language and details of the fluoridation campaign. The social items are the latest raffle winners and winners of colouring competitions.

\section{THANKS TO THE PATIENTS FOR THEIR \\ HELP}

This year Wessington Way held 'patient of the year' awards to show their patients how much they appreciate their help and involvement. All members of staff and any patients who wished, could nominate up to three patients with an explanation of why they nominated that person.

Martin Anderson held a garden party where the awards were given out. The categories included an award for "patient of the year', 'young patient of the year', 'patient who has overcome anxiety' and a special award for 'services to the practice'.

The party was a real community event, MEP Martin Callanan presented one of the awards, as did the chairman of the practice forum, and even some of the practice suppliers joined in the fun. The winners all received engraved trophies and the finalists a set of engraved wine glasses. The winner of the 'young patient of the year' award was so pleased with his cinema ticket prize that he said he felt he had ‘jewels

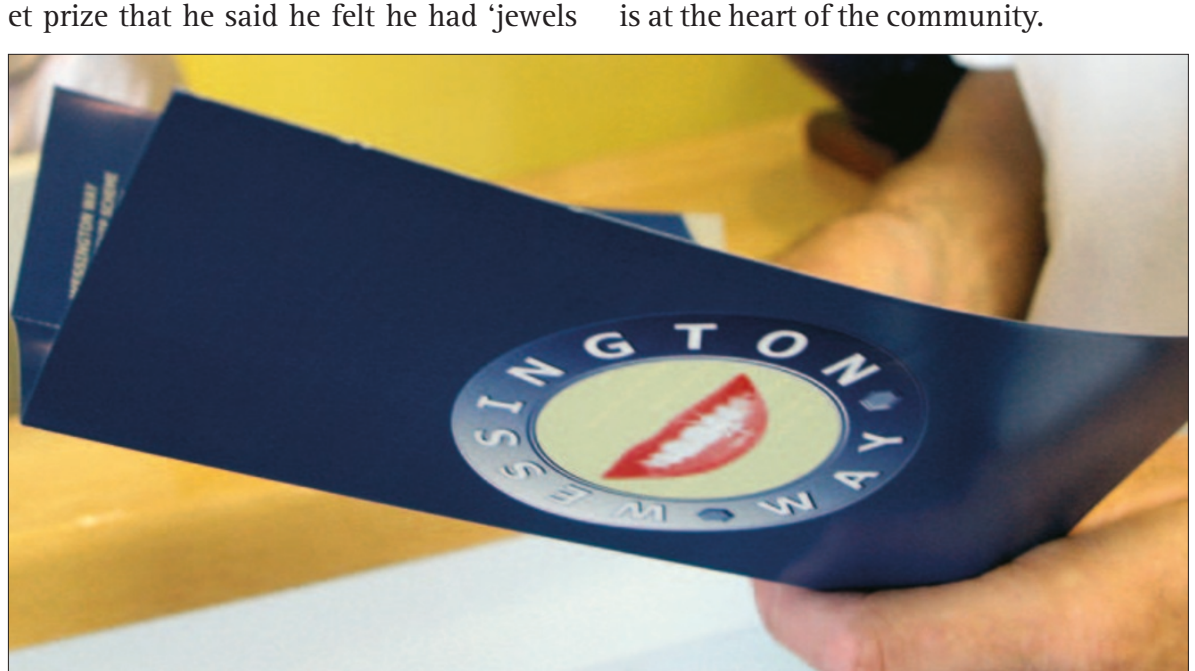

A patient information leaflet

\section{How the teams got involved}

To participate, each entrant submitted a nomination form with documentation supporting their claims of excellence in dental patient care, specifying which category or categories they wanted to be entered for:

- Excellence in children's dental care

- Excellence in treating those with special healthcare needs

- Excellence in patient information and involvement

- Excellence in creating a patient friendly environment

- Excellence in the development of good practice

round his heart'. The many initiatives set up by the practice have ensured that patients are fully involved every step of the way. By keeping patients both young and old informed and updated on decisions and initiatives, the practice has ensured that it is at the heart of the community. 